\title{
Sex differences in type 2 diabetes: focus on disease course and outcomes
}

This article was published in the following Dove Press journal:

Diabetes, Metabolic Syndrome and Obesity:Targets and Therapy 16 September 2014

Number of times this article has been viewed

\author{
Lisa Arnetz ${ }^{1,2}$ \\ Neda Rajamand Ekberg ${ }^{1,2}$ \\ Michael Alvarsson ${ }^{1,2}$ \\ 'Department of Molecular \\ Medicine and Surgery, Karolinska \\ Institutet, ${ }^{2}$ Department of \\ Endocrinology, Metabolism and \\ Diabetes, Stockholm, Sweden
}

Correspondence: Michael Alvarsson Department of Endocrinology, Diabetes and Metabolism, D2:04, Karolinska University Hospital Solna, 17176 Stockholm, Sweden

$\mathrm{Tel}+46851772862$

Fax +46851773096

Email michael.alvarsson@karolinska.se
Background: Women with type 2 diabetes (T2D) are less likely to reach the goals for hemoglobin $\mathrm{A}_{1 \mathrm{c}}$ compared with men, and have higher all-cause mortality. The risk of cardiovascular disease is elevated among both men and women with T2D, however, the risk has declined among men over recent years while it remains stationary in women. Reasons for these sex differences remain unclear, and guidelines for diabetes treatment do not differentiate between sexes. Possible causes for varying outcome include differences in physiology, treatment response, and psychological factors. This review briefly outlines sex differences in hormonal pathophysiology, and thereafter summarizes the literature to date on sex differences in disease course and outcome.

Methods: Systematic searches were performed on PubMed using "sex", "gender", and various glucose-lowering therapies as keywords. Earlier reviews are summarized and results from individual studies are reported. Reference lists from studies were used to augment the search.

Results: There is an increased risk of missing the diagnosis of T2D when screening women with only fasting plasma glucose instead of with an oral glucose tolerance test. The impact of various risk factors for complications may differ by sex. Efficacy and side effects of some glucose-lowering drugs differ between men and women. Men with T2D appear to suffer more microvascular complications, while women have higher morbidity and mortality in cardiovascular disease and also fare worse psychologically.

Conclusion: Few studies to date have focused on sex differences in T2D. Several questions demand further study, such as whether risk factors and treatment guidelines should be sexspecific. There is a need for clinical trials designed specifically to evaluate sex differences in efficacy and outcome of the available treatments.

Keywords: type 2 diabetes, gender, sex, complications, cardiovascular disease, treatment

\section{Introduction}

The prevalence of type 2 diabetes (T2D) is rising globally, due to, among other factors, obesity, physical inactivity, and aging superimposed on a genetic predisposition. ${ }^{1,2}$ The World Health Organization estimates that the number of people with T2D will increase to 366 million by the year 2030. Hyperglycemia and diabetes are important causes of morbidity and mortality, due to cardiovascular disease (CVD), nephropathy, neuropathy, foot ulcers, and retinopathy.

Previous studies have shown that T2D affects women disproportionately. ${ }^{3}$ Women with T2D generally have poorer glycemic control ${ }^{4-6}$ and are less likely to reach the goals for hemoglobin $\mathrm{A}_{1 \mathrm{c}}\left(\mathrm{HbA}_{1 \mathrm{c}}\right)$ compared with men. ${ }^{7,8}$ Women with diabetes have higher all-cause mortality. ${ }^{9}$ Among men with T2D, the mortality rate in CVD has declined at a rate comparable with non-diabetic men over the past decades but there 
is still an almost three-fold increase due to diabetes. The risk has decreased among non-diabetic women, but has not declined in women with T2D and remains nearly four-fold higher. ${ }^{10}$ Reasons for these sex differences remain unclear, and guidelines for diabetes treatment do not differentiate between sexes. While many studies have included patients of both sexes, few have analyzed for sex differences. ${ }^{11}$ Possible causes for varying outcome include differences in physiology, treatment response, and psychological factors. This review will briefly outline sex differences in hormonal pathophysiology, and thereafter summarize the literature to date on sex differences in disease course and outcome.

\section{Methods}

A survey of the English-language literature was conducted on PubMed, using the search terms "sex", "gender", "sex-specific", and "gender-specific" in combination with "diabetes", "metformin", "sulphonylurea", "glipizide", "glibenclamide", "glyburide", "glimepiride", "meglitinide", "repaglinide", "rosiglitazone", "pioglitazone", "thiazolidinedione", "exenatide", "liraglutide", "sitagliptin", "vildagliptin", "linagliptin", "saxagliptin", "alogliptin", "SGLT", and "dapagliflozin". No specific search was performed regarding insulin therapies, as review articles on this subject were found via the searches. Further searches were performed combining the term "diabetes" with "sex"/"gender" and "retinopathy", "nephropathy", "neuropathy", and "gastroparesis". The bibliographies of the articles were used to further augment the search. We have attempted to summarize results from previous reviews in the field as well as describing newer studies. Gestational diabetes, type 1 diabetes, and T2D in children and adolescents are not discussed in this review.

\section{Body composition}

The prevalence of obesity is similar between men and women overall, although sex differences exist in some populations. ${ }^{12}$ Especially abdominal obesity is associated with T2D and CVD in both sexes, especially post-menopausal women. ${ }^{13}$

Women have a higher percentage of body fat ${ }^{14}$ and more often develop peripheral adiposity, whereas men accumulate fat centrally (ie, android obesity). ${ }^{15}$ About one third of overweight women develop the android phenotype. ${ }^{16}$ After menopause, the tendency toward male-type obesity and lipid profile increases in women. ${ }^{17,18}$ Among patients with T2D, $40 \%$ of men but as many as $70 \%$ of women display abdominal obesity, suggesting the association between T2D and abdominal obesity is stronger in women than in men. ${ }^{13}$

\section{Visceral adipose tissue}

Visceral adipose tissue (VAT) and subcutaneous adipose tissue (SAT) differ in their sensitivity to insulin, sex hormones, and adrenergic stimulation. ${ }^{18}$ At the same body mass index (BMI), men are often more insulin resistant than women due to a tendency toward VAT accumulation. ${ }^{19}$

Visceral adipocytes have a higher tendency toward lipolysis due to lower sensitivity to insulin's inhibiting effect and higher expression of glucocorticoid receptors, which contribute to lipolysis. ${ }^{16,20}$ Compared to SAT, VAT thereby releases more free fatty acids (FFAs); it also produces inflammatory cytokines such as tumor necrosis factor $\alpha$ (TNF $\alpha)$. These substances are transported via the portal vein to the liver, where they induce hepatic insulin resistance and an atherogenic lipid profile. ${ }^{16}$ Lower tendency to developing visceral adiposity, at least before menopause, may explain why women are relatively protected from T2D and CVD compared with men. ${ }^{15,21}$

\section{Metabolic syndrome}

Metabolic syndrome (MetS) is a cluster of risk factors for CVD, in essence insulin resistance, hypertension, dyslipidemia, and abdominal obesity although the details of the definition vary. ${ }^{18}$ Sex differences in the prevalence and components of MetS have been reviewed by Regitz-Zagrosek et al. ${ }^{18,22}$ MetS has previously been more common in men than women, but the prevalence is increasing in women due to increasing obesity. ${ }^{22}$

Low and very low density lipoprotein (LDL and VLDL) and triacylglycerol (TG) are lower in pre-menopausal women compared with men, whereas high density lipoprotein (HDL) is higher. ${ }^{15}$ After menopause, an increase in VAT occurs in parallel with increased prevalence of MetS, with a more atherogenic lipid profile and more hypertension. ${ }^{18}$ In the Multinational MONItoring of trends and determinants in CArdiovascular disease (MONICA) study, hypertension and apolipoproteins were the strongest contributors to MetS in men. In women, high weight and waist circumference as well as low HDL were more important contributors. ${ }^{23}$

\section{Prevalence of abnormal glucose tolerance and T2D}

Impaired fasting glucose (IFG) is more common in men, whereas impaired glucose tolerance (IGT) dominates among women, who instead have lower fasting plasma glucose (FPG). ${ }^{18,22,24}$ Insulin resistance is closely linked to IFG, whereas disturbed $\beta$-cell function is related to elevated post-load glucose, ie, IGT. ${ }^{25,26}$ 
T2D has often been found to be more common in $\operatorname{men}^{27}$ but the prevalence is equal or higher among women in some populations, possibly due to women living longer. ${ }^{24,28}$

\section{Risk factors for T2D}

Being overweight is the strongest risk factor for developing T2D in both sexes. ${ }^{24}$ However, the BMI "threshold" at which insulin resistance develops differs depending on ethnicity, heredity, and sex. ${ }^{29}$ Women are protected up to a higher BMI, as they accumulate lipids in SAT which induces less harm than that in VAT which occurs in men. ${ }^{29,30}$ High waist circumference after correcting for height is a risk factor in both sexes, but may be a stronger predictor in women. ${ }^{31,32}$ Age, a family history of T2D, and low HDL are risk factors for T2D in both men and women. High daily alcohol consumption, smoking, and systolic hypertension are stronger risk factors in men, whereas elevated $\mathrm{TG}$ and physical inactivity are stronger in women. ${ }^{24}$

\section{Methods of diagnosing T2D}

In a German study, undiagnosed T2D was more common in men than women $(9.3 \%$ versus $6.9 \%)$. Half of the women found to have previously unknown T2D were only detected by 2 hour plasma glucose during an oral glucose tolerance test (OGTT), and would therefore have been missed if only screened by FPG. ${ }^{33}$ The use of $\mathrm{HbA}_{1 \mathrm{c}}$ to diagnose T2D may also be a less reliable method in populations in which T2D is best diagnosed by 2 hour plasma glucose than by FPG. ${ }^{33}$

\section{Sex differences in hormonal pathophysiology}

Hormones regulating glycemic control are affected by sex and body type. These differences are outlined in brief below; details are available in the cited review articles.

\section{Cortisol}

High cortisol levels increase insulin resistance, gluconeogenesis, the tendency toward accumulation of VAT, hypertension, and dyslipidemia. ${ }^{13,34}$ Cortisol levels may be elevated in visceral obesity due to increased reduction of cortisone to cortisol by the enzyme 11 $\beta$-hydroxysteroid dehydrogenase-1 (11ßHSD-1) in VAT. ${ }^{13}$ Some studies have suggested sex differences in cortisol production via the hypothalamus-pituitaryadrenal axis and/or 11ßHSD-1, but results have varied between studies and the clinical implications remain unclear. ${ }^{35}$

\section{Sex hormones}

Sex hormones are fundamental to the biological differences between men and women, regulating not only sex characteristics and fertility but also metabolism and adipose tissue. ${ }^{36}$ There are various articles regarding differences in sex hormone receptors. ${ }^{37,38}$

\section{Testosterone}

In men, testosterone stimulates lipolysis in adipose tissue. Low testosterone levels are associated with abdominal obesity and insulin resistance in men, ${ }^{39}$ and are an independent risk factor for developing T2D. ${ }^{40}$ Insulin sensitivity, visceral fat mass, blood pressure, and plasma lipids improve with testosterone substitution. ${ }^{41,42}$ Men with higher testosterone levels (15.6-21.0 nmol/L) had a 42\% lower risk of developing $\mathrm{T} 2 \mathrm{D}$ in a meta-analysis. ${ }^{43}$

Unlike for men, increased androgen levels induce insulin resistance in women ${ }^{44}$ and increase the risk of T2D and CVD. ${ }^{43,45}$ This is exemplified in polycystic ovary syndrome (PCOS), which is associated with hyperandrogenism, insulin resistance, and an increased risk of developing T2D ${ }^{46}$ Mechanisms by which androgens induce insulin resistance in women include reduced glucose uptake ${ }^{47}$ and increased lipolysis, especially from VAT. ${ }^{36}$ Androgen levels may be elevated in women with central obesity and perhaps T2D. ${ }^{43,48}$ Interestingly, women with T2D have higher bone density than non-diabetic controls, perhaps due to the anabolic effects of androgens. ${ }^{49}$

\section{Sex-hormone binding globulin}

Free (active) testosterone levels are regulated by sex-hormone binding globulin (SHBG). Insulin regulates SHBG by inhibiting its synthesis, and hyperinsulinemia thus results in low SHBG. ${ }^{46}$ Low SHBG is seen in men and women with abdominal obesity; in women, this contributes to hyperandrogenemia. ${ }^{13}$ Elevated androgen levels in PCOS result from a vicious cycle, in which high insulin levels stimulate ovarian androgen synthesis as well as lowering SHBG, which in turn further exacerbates hyperandrogenemia and thereby the insulin resistance. ${ }^{46}$ High SHBG levels are protective against T2D regardless of sex, probably since low SHBG is a marker of hyperinsulinemia; however, it is more protective in women than in men. ${ }^{43}$

\section{Estrogen}

Estrogen is synthesized in the ovaries in premenopausal women, and via conversion from testosterone by aromatase in adipose tissue in men and women. ${ }^{22}$ Obesity is associated with increased expression of aromatase messenger RNA in both sexes. ${ }^{50}$ Elevated estradiol levels may be a risk factor for insulin resistance in men, whereas in women the decrease in estrogen levels after menopause coincides with increased risk 
of elevated FPG.${ }^{24}$ Hormone replacement therapy may reduce insulin resistance, but also encompasses risks. ${ }^{11,24}$

\section{Growth hormone and insulin-like growth factor-I}

Growth hormone (GH) exerts anabolic effects, mainly via insulin and insulin-like growth factor-I(IGF-I), but is lipolytic and increases insulin resistance in fasting/starvation. IGF-I contributes to uptake of glucose and FFAs, and improves insulin sensitivity. ${ }^{51}$ Sex differences in GH contribute to differences in body composition between men and women, and have been reviewed by Gatford et al..$^{52}$ Women have higher mean GH levels and GH pulse amplitudes compared with men. ${ }^{52}$ There are no sex differences in serum IGF-I levels in healthy subjects, or in the decline in IGF-I that occurs with age. ${ }^{53,54}$ However, serum levels of IGF binding protein-1 (IGFBP-1), which regulates IGF-I bioavailability, ${ }^{55}$ are higher in women compared with men. ${ }^{31,56}$ This is partially due to a stimulatory effect of estrogen on IGFBP-1 synthesis. ${ }^{57}$

\section{Adiponectin}

Adiponectin is a hormone synthesized exclusively in adipose tissue. ${ }^{58}$ It increases insulin sensitivity of the liver and skeletal muscle. ${ }^{59}$ Adiponectin synthesis is stimulated by insulin, IGF-I, and peroxisome-proliferator activated receptor $\gamma$ (PPAR $\gamma$ ) agonists, and inhibited by glucocorticoids, $\beta$-adrenergic stimulation, cytokines, and androgens. ${ }^{60-62}$ Adiponectin levels decrease with insulin resistance and obesity ${ }^{63}$ which may explain why they are higher in women versus men, ${ }^{29,64}$ and in controls versus patients with T2D. Low levels are a marker of insulin resistance, ${ }^{63}$ whereas high levels have been associated with reduced risk of T2D ${ }^{65}$ and CVD. ${ }^{66}$

\section{Leptin}

Leptin is an adipokine produced in the adipose tissue, involved in control of food intake. ${ }^{18}$ Obesity is associated with "leptin resistance", ie, reduced signaling through leptin receptors. ${ }^{67}$ Leptin levels are higher in women than in men, reflecting greater total percent fat mass ${ }^{68}$ Leptin is positively correlated with free estrogen in post-menopausal women, and with free testosterone in men. ${ }^{69}$ Increased leptin levels are associated with CVD in men, ${ }^{70,71}$ while they may be protective against $\mathrm{CVD}$ in women. ${ }^{72}$

\section{Metabolic control}

Women generally have poorer glycemic control ${ }^{4-6}$ and are less likely to reach the goals for $\mathrm{HbA}_{1 \mathrm{c}}$ compared with men, ${ }^{7,8}$ despite better diet and more frequent self-monitoring of blood glucose. ${ }^{6}$ Men are, however, more likely to be admitted to hospital with diabetes-related conditions or to present with excessively high blood sugar levels. ${ }^{73}$

\section{Therapy to improve glycemic control}

Studies on glucose-lowering therapies often include women but are rarely designed specifically to analyze for sex differences in efficacy, pharmacodynamics, pharmacokinetics or side effects. ${ }^{16,24}$ Some of the pivotal studies on treatment of T2D have looked at the effect of sex on outcome, eg, the Action to Control Cardiovascular Risk in Diabetes (ACCORD) ${ }^{74}$ and Action in Diabetes and Vascular disease: Preterax and Diamicron Modified Release Controlled Evaluation (ADVANCE) ${ }^{75}$ trials; most others, eg the United Kingdom Prospective Diabetes Study (UKPDS) ${ }^{76}$ and A Diabetes Outcome Progression Trial (ADOPT) ${ }^{77}$ trials, have not. Most studies found, when we performed searches on diabetes therapies in relation to sex, were listed only because they included women or stratified for sex; among those with results pertinent to women, studies were most often not primarily designed to look for sex differences, or were focused on PCOS. Many of the studies focused on sex were animal studies.

In a meta-analysis focused on the effect of sex on outcome with treatment to improve metabolic control in T2D, various forms of insulin, oral antidiabetic drugs (OADs), and dietary interventions all had less effect on $\mathrm{HbA}_{1 \mathrm{c}}$ in women compared to men. ${ }^{78}$

\section{Lifestyle interventions}

Few studies have compared the efficacy of exercise interventions, or the benefits of various types of exercise, in men versus women. Intensive lifestyle intervention appeared to be equally effective in preventing T2D in men and women in the Diabetes Prevention Program (DPP) ${ }^{79}$ although weight loss $>3 \%$ prevented development of T2D more effectively in men. ${ }^{80}$ However, among patients with T2D, women were found to be more successful at losing weight after initiation of glucose-lowering therapy. ${ }^{81}$

While some studies have shown that physical activity decreases the risk of CVD and cardiovascular events ${ }^{82}$ and C-reactive protein (CRP; a marker of inflammation) ${ }^{83}$ more in women, beneficial effects on risk factors for CVD have also been shown in studies with men. Thus, exercise is important to reduce morbidity and mortality in patients with T2D regardless of sex. ${ }^{11}$

\section{Glucose-lowering therapy}

In an Italian study, women were more often treated with metformin, thiazolidinediones (TZDs) or insulin 
as well as combination therapy. ${ }^{84} \mathrm{~A}$ German study reported men to have less intense pharmacological intervention and also less contact with their general practitioner. ${ }^{85}$ However, other studies have reported the opposite, with more intense pharmacological treatment in men. ${ }^{86,87}$

\section{Metformin}

The pharmacodynamics of metformin do not differ by sex in healthy young adults. ${ }^{88}$ Metformin has more beneficial effects on myocardial fatty acid and glucose metabolism in men compared with women. ${ }^{89}$ Women treated with metformin to prevent T2D in the DPP reported more adverse events than men did (15\% versus $10 \%)$, and were also less adherent to treatment..$^{90}$ In one study, men admitted to an intensive care unit with lactic acidosis secondary to metformin therapy had higher mortality than women, ${ }^{91}$ while another found that treatment with metformin in spite of having a contraindication to such therapy was associated with a higher rate of hospitalization and mortality in women. ${ }^{22}$

\section{Thiazolidinediones}

TZDs are PPAR $\gamma$ agonists; insulin-sensitizing drugs used in the treatment of T2D. ${ }^{93}$ Although some studies have suggested that TZDs may be more effective in women compared with men, ${ }^{9496}$ the majority of larger studies have not reported sex-specific differences. ${ }^{93}$ There may be sex differences in pharmacokinetics, resulting in higher plasma levels in females. ${ }^{68}$ TZDs lower CRP and leptin more in women than men. ${ }^{24,97}$ However, women may also be more sensitive to side effects. Hypoglycemia ${ }^{98}$ and fractures ${ }^{68}$ are more common in women than men on TZDs. We have found pioglitazone to increase basal serum cortisol in women but not in men, although the clinical significance of this is unclear. ${ }^{99}$ Women treated with rosiglitazone had higher mortality than men, while no differences were seen for other treatments eg, metformin. ${ }^{100}$

\section{Medications affecting the incretin system}

Sex does not appear to affect the pharmacokinetics, efficacy or safety of exenatide or liraglutide. ${ }^{101-103}$ Predictors of weight loss and achievement of target $\mathrm{HbA}_{1 \mathrm{c}}$ differed between men and women treated with exenatide (as well as metformin). ${ }^{104}$ No impact of sex has been found on the pharmacokinetics of vildagliptin or saxagliptin, ${ }^{105,106}$ while one study found that women treated with sitagliptin or alogliptin more frequently reported hypoglycemia. ${ }^{107}$

\section{Other oral antidiabetic agents}

No studies were found focused specifically on the impact of sex on treatment with sulphonylureas or dapagliflozin. Those that tested for the effect of sex did not find any such effect. ${ }^{108-110}$

\section{Insulin therapy}

Men on insulin glargine or neutral protamine Hagedorn (NPH) insulin were in a meta-analysis more likely to reach $\mathrm{HbA}_{1 \mathrm{c}}$ targets, despite women having a greater reduction in FPG and higher weight-adjusted insulin doses. ${ }^{78}$ Hypoglycemic events are both more common and more severe in women ${ }^{47}$ This may in part be explained by women having lower counter-regulatory responses to hypoglycemia. ${ }^{111,112}$ Fear of such episodes are an important underlying reason for unwillingness to adhere to intensive insulin regimes. ${ }^{113}$

\section{Complications}

With the exceptions of CVD, few studies have focused exclusively on sex differences in complications of T2D. In general, the available data suggest that male sex is associated with a higher risk of both microvascular and macrovascular complications, although there are conflicting data. ${ }^{24,114}$

\section{Diabetic retinopathy}

Some studies have reported female sex to predispose to diabetic retinopathy (DRP); ${ }^{115,116}$ one also reported an association with cytokine levels. ${ }^{116}$ Others have found no differences in DRP frequency or severity between the sexes, ${ }^{84}$ or an increased risk in men. ${ }^{117,118}$ Proliferative DRP is a risk factor of CVD in both sexes, but several studies have found it to be a stronger risk factor in women. ${ }^{24}$

\section{Neuropathy}

Few studies have looked for sex differences in neuropathy in T2D. Two studies have found men to show signs of diabetic neuropathy more frequently, ${ }^{24}$ and to develop neuropathy earlier. ${ }^{119}$

\section{Nephropathy}

Preclinical studies suggest protective effects of estrogen against nephropathy, as estrogen inhibits the reninangiotensin-aldosterone system whereas testosterone upregulates it. Estrogen also increases the synthesis of nitric oxide (a marker of endothelial function) and reduces collagen synthesis by mesangial cells. ${ }^{24}$ Nearly all degrees of nephropathy are more common in men than women, with the exception of stage 5 chronic kidney disease. ${ }^{82}$ One study found albuminuria is a stronger risk factor for 
CVD among men with T2D compared with women. ${ }^{120}$ These differences may be due to sex differences in other factors such as hypertension. ${ }^{24}$ Genetic factors may influence the risk of developing nephropathy differently in men and women. ${ }^{11}$

\section{Gastroparesis}

The prevalence and severity of symptoms of gastroparesis have been reported to be higher among women than men with T2D, particularly among obese women with long duration of $\mathrm{T} 2 \mathrm{D}$ and high $\mathrm{HbA}_{1 \mathrm{c}}{ }^{\cdot 121}$

\section{Foot ulcers and lower limb amputations}

Foot ulcers, gangrene, and lower limb amputation are more prevalent in men with T2D compared with women. ${ }^{41,122}$ In one study, men diagnosed with T2D before 65 years of age were at especially high risk of foot ulcers and amputations, whereas for women the risk of amputation increased with age. ${ }^{123}$ The mortality risk in conjunction with lower limb amputation may, however, be higher in women. ${ }^{122}$

\section{Cardiovascular disease}

Sex differences in CVD have been studied more intensely than those for other diabetic complications. Most results point to increased risk and poorer outcome in women. Explanations for this include differences in hormonal and vascular pathophysiology, differing impact of risk factors, and less aggressive treatment both preventively and following an event.

\section{Epidemiology}

Women are relatively protected from CVD before menopause, ${ }^{124}$ while after menopause the risk of CVD increases to levels equal to those in men. ${ }^{68,125}$ Despite this, it has not been confirmed that hormone replacement therapy after menopause decreases the risk of CVD. ${ }^{126}$

Insulin resistance and $\mathrm{T} 2 \mathrm{D}$ are associated with an increased risk of CVD, up to $50 \%$ more so in women than men. ${ }^{11,22,24}$ It appears that T2D obliterates the protective effect of estrogen. ${ }^{24}$ In a meta-analysis of subjects $<60$ years of age, with high risk of developing CVD, the incidence of CVD during follow-up was lower in women compared to men in the absence of T2D, while in the presence of T2D the risks were similar. ${ }^{127}$ The risk of CVD increases at least three- to six-fold in women with T2D, compared with two- to fourfold in diabetic men. ${ }^{128,129}$ The true frequency of CVD may still be underestimated in women with T2D, as they are more likely than men to have asymptomatic defects in myocardial perfusion. ${ }^{130}$
Carotid stenosis and ischemic stroke are more common in women than in men with MetS and T2D. Results from studies have varied as to whether there are sex differences in the incidence of stroke in T2D patients, but the mortality rate may be higher in women. ${ }^{24}$

Diabetes is also a risk factor for coronary artery spasm in women with $\mathrm{T} 2 \mathrm{D},{ }^{131}$ while men with $\mathrm{T} 2 \mathrm{D}$ suffer more peripheral arterial disease. ${ }^{121}$ Insulin resistance has a negative impact on metabolism in the myocardium, which may explain why T2D is associated with an increased risk of heart failure. ${ }^{132}$ While survival in heart failure is generally higher in women than in men, this sex difference is attenuated in T2D. ${ }^{132}$

\section{Risk factors for CVD}

T2D is associated with increased frequency of risk factors for CVD regardless of sex, but the increase is relatively greater in women. ${ }^{29}$

Abdominal obesity, which increases in women after menopause, is a stronger risk factor for CVD in women compared with men. ${ }^{22,133}$ Obese women with T2D also have higher frequency of left ventricular dysfunction and arterial stiffness than men. ${ }^{24}$ Hyperinsulinemia has not been directly linked to an increased incidence of CVD in either sex. ${ }^{68}$

Women with T2D are more likely than men to have hypertension, ${ }^{134,135}$ with more deleterious effects on cardiovascular health. ${ }^{24}$ Total cholesterol and LDL may be more important risk factors for CVD in men, while TG has a greater impact in women ${ }^{22,24}$ and is often elevated in women with T2D. ${ }^{136}$ Low HDL is a stronger predictor in both nondiabetic and diabetic women compared with men. ${ }^{137}$ Women with T2D have higher LDL and blood pressure at diagnosis despite lower $\mathrm{HbA}_{1 \mathrm{c}}$, and are less likely than men to subsequently meet target levels for these risk factors. ${ }^{84,138}$

\section{Prognosis and treatment outcome}

CVD and myocardial infarction are associated with increased mortality in women with T2D compared with men. ${ }^{139-141}$ The relative risk for mortality due to CVD is higher in diabetic compared with non-diabetic women, whereas no such difference is seen for men. ${ }^{142}$ T2D may even be a stronger risk factor for mortality, than a history of previous CVD, in women with T2D. ${ }^{143}$

The effect of certain medications may also differ between the sexes in some clinical conditions. Angiotensin-converting enzyme (ACE)-inhibitors and $\beta$-blockers reduce mortality in men but not in women with asymptomatic left ventricular dysfunction, while both sexes benefit in symptomatic 
dysfunction. ${ }^{144}$ Most studies on statins have been conducted in men, and a meta-analysis showed that they might have less effect on mortality in women. ${ }^{145}$ Similarly, ezetemibe ${ }^{146}$ and fibrates ${ }^{93}$ may be less effective in women compared with men with T2D. Among patients with T2D, aspirin as primary prevention reduces the risk of stroke more in women, but that of myocardial infarction more in men. ${ }^{147}$ However, there is a lack of trials specifically designed to evaluate sex differences in pharmacological treatment of CVD, and the exclusion of women of fertile age may affect the results. ${ }^{148}$

Poorer outcome after percutaneous transluminal coronary angioplasty was found in older studies but not in more recent ones, including studies regarding drug-eluting stents. ${ }^{24}$ After coronary angioplasty stenting, the odds ratio for restenosis after adjustment for age was 1.30 (95\% confidence interval [CI] 0.99-1.70) in patients with T2D compared with nondiabetics in a meta-analysis of six studies. ${ }^{149}$ The rate of restenosis has either been found not to differ between men and women, ${ }^{149}$ or even to be lower in women with T2D. ${ }^{150,151}$

\section{Hypothesized causes of increased CVD morbidity and mortality in women with T2D}

Differences in blood pressure, lipids, etc may partly explain the increased mortality in female compared with male diabetes patients according to some, ${ }^{141,152}$ but not all, studies. ${ }^{153}$ It has been speculated that elevated androgen levels contribute to the increased risk of CVD in women with T2D, but studies on women with PCOS have not confirmed this hypothesis. ${ }^{13}$

The coagulation system and endothelial function may be more disturbed in women with T2D. While women normally have higher fibrinolytic potential and endothelial function (nitric oxide availability) compared with men, these protective effects are reduced in $\mathrm{T}_{2} \mathrm{D}^{154}$ and the coagulation system is reset to a more pro-thrombotic state. ${ }^{155}$ Inflammation leads to endothelial dysfunction and insulin resistance, and is associated with worse cardiovascular outcomes in women. ${ }^{24}$ Compared with more "classic" risk markers, those for inflammation and angiogenesis (TNF $\alpha, \mathrm{CRP}$, vascular endothelial growth factor) better account for the increased risk of CVD in women with T2D. ${ }^{156}$ Inflammation (elevated CRP) may explain the increased risk of coronary artery spasm in diabetic women. ${ }^{131}$ Cellular defense mechanisms against oxidative stress may also be relatively more impaired in women. ${ }^{157}$

Women may be less aggressively treated during an acute cardiovascular event, and/or receive less primary or secondary prevention of CVD. During the acute event, cardiac catheterization, percutaneous transluminal coronary angioplasty, and coronary artery bypass graft surgery are less frequently used in women. ${ }^{24}$ Diagnosis may be delayed as women less frequently report "classic" symptoms, such as central chest pain. ${ }^{158}$ Data on medication for risk factors vary between populations. In some cohorts, more men than women were treated with lipid-lowering drugs, ${ }^{8}$ ACE-inhibitors and/or calcium channel blockers, ${ }^{86}$ and/or aspirin. ${ }^{8,84}$ Others have reported a higher degree of use of lipid-lowering and anti-hypertensive agents in women. ${ }^{84}$

\section{Cancer}

T2D is associated with an increased risk of several forms of cancer, eg, pancreatic, renal, colorectal, liver, endometrial, breast, and bladder cancer. Proposed mechanisms include endogenous and exogenous hyperinsulinemia, IGF-I, and inflammation. ${ }^{159,160}$

T2D may be a stronger risk factor for colorectal cancer in women than in men, ${ }^{161}$ while bladder cancer is more common in men with T2D. ${ }^{162}$ Mortality rates in cancer are higher in female cancer patients with T2D compared to men. ${ }^{163}$ The mortality rates in the same study were also higher for sexspecific cancers (ovary, uterus, prostate) compared with in non-diabetic cancer patients.

Oral insulin sensitizers, ie, metformin and particularly TZDs, are associated with $21 \%-32 \%$ reduced risk of incident cancer compared with treatment with insulin secretagogues (sulphonylurea or meglitinide), even after correction for multiple other risk factors, and especially in women. ${ }^{164}$

\section{Depression and quality of life}

Sex differences in the ability to cope with life with diabetes have recently been reviewed by Siddiqui et al. ${ }^{165}$ In summary, women with T2D appear to fare worse psychologically, and suffer more depression, anxiety, and low energy levels compared with diabetic men. Women with T2D also have more depression than non-diabetic women. ${ }^{166}$ Social class and employment status (ie, psychosocial stress) are stronger predictors of T2D in women than in men in some, ${ }^{167}$ but not all studies. ${ }^{168,169}$ These factors could potentially contribute to the lower degree of achievement of $\mathrm{HbA}_{1 \mathrm{c}}$ targets in women compared with men. Of note, even though the prevalence is higher in women, depression and anxiety are more common among both men and women with T2D compared with the general population. ${ }^{170}$ Depression may even be a more important reason for non-compliance with diabetes treatment among men compared to women. ${ }^{171}$ 


\section{Summary and conclusion}

In summary, a number of studies have suggested sex differences in risk factors and treatment outcome both for T2D and its complications. Data indicate that men with T2D suffer more microvascular complications, while women have higher morbidity and mortality in CVD and also fare worse psychologically. There is a reasonable degree of evidence for some differences, eg, the increased risk of missing the diagnosis of T2D when screening women with only FPG instead of OGTT. However, in most areas discussed in this review, there is still a lack of knowledge on the true impact of sex. Several questions demand further study, such as whether elevated TG and/or low HDL should be considered a stronger risk factor in women or whether different risk factors altogether need to be implemented; whether treatment with longer-acting insulins will benefit women more due to their increased risk of hypoglycemia; and, in the long run, whether treatment guidelines should be different for men and women. There is especially a need for clinical trials designed specifically to evaluate sex differences in efficacy and outcome of the available treatments.

\section{Disclosure}

The authors have no conflicts of interest to declare.

\section{References}

1. Danaei G, Finucane MM, Lu Y, et al. National, regional, and global trends in fasting plasma glucose and diabetes prevalence since 1980: Systematic analysis of health examination surveys and epidemiological studies with 370 country-years and 2(middle dot)7 million participants. Lancet. 2011;378(9785):31-40.

2. Agardh EE, Ahlbom A, Andersson T, et al. Work stress and low sense of coherence is associated with type 2 diabetes in middle-aged Swedish women. Diabetes Care. 2003;26(3):719-724.

3. Misra R, Lager J. Ethnic and gender differences in psychosocial factors, glycemic control, and quality of life among adult type 2 diabetic patients. J Diabetes Complications. 2009;23(1):54-64.

4. Shalev V, Chodick G, Heymann AD, Kokia E. Gender differences in healthcare utilization and medical indicators among patients with diabetes. Public Health. 2005;119(1):45-49.

5. Tang YH, Pang SM, Chan MF, Yeung GS, Yeung VT. Health literacy, complication awareness, and diabetic control in patients with type 2 diabetes mellitus. J Adv Nurs. 2008;62(1):74-83.

6. Chiu CJ, Wray LA. Gender differences in functional limitations in adults living with type 2 diabetes: biobehavioral and psychosocial mediators. Ann Behav Med. 2011;41(1):71-82.

7. Nilsson PM, Theobald H, Journath G, Fritz T. Gender differences in risk factor control and treatment profile in diabetes: a study in 229 swedish primary health care centres. Scand J Prim Health Care. 2004;22(1): 27-31.

8. Wexler DJ, Grant RW, Meigs JB, Nathan DM, Cagliero E. Sex disparities in treatment of cardiac risk factors in patients with type 2 diabetes. Diabetes Care. 2005;28(3):514-520.

9. Roche MM, Wang PP. Sex differences in all-cause and cardiovascular mortality, hospitalization for individuals with and without diabetes, and patients with diabetes diagnosed early and late. Diabetes Care. 2013;36(9):2582-2590.
10. Gregg EW, Gu Q, Cheng YJ, Narayan KM, Cowie CC. Mortality trends in men and women with diabetes, 1971 to 2000. Ann Intern Med. 2007;147(3):149-155.

11. Legato MJ, Gelzer A, Goland R, et al. Gender-specific care of the patient with diabetes: review and recommendations. Gend Med. 2006;3(2): 131-158.

12. Pilote L, Dasgupta K, Guru V, et al. A comprehensive view of sex-specific issues related to cardiovascular disease. CMAJ. 2007;176(6):S1-S44.

13. Pasquali R, Vicennati V, Gambineri A, Pagotto U. Sex-dependent role of glucocorticoids and androgens in the pathophysiology of human obesity. Int J Obes (Lond). 2008;32(12):1764-1779.

14. Mattsson C, Olsson T. Estrogens and glucocorticoid hormones in adipose tissue metabolism. Curr Med Chem. 2007;14(27):2918-2924.

15. Williams CM. Lipid metabolism in women. Proc Nutr Soc. 2004;63(1):153-160.

16. Wajchenberg BL. Subcutaneous and visceral adipose tissue: their relation to the metabolic syndrome. Endocr Rev. 2000;21(6):697-738.

17. Haarbo J, Marslew U, Gotfredsen A, Christiansen C. Postmenopausal hormone replacement therapy prevents central distribution of body fat after menopause. Metabolism. 1991;40(12):1323-1326.

18. Regitz-Zagrosek V, Lehmkuhl E, Weickert MO. Gender differences in the metabolic syndrome and their role for cardiovascular disease. Clin Res Cardiol. 2006;95(3):136-147.

19. Geer EB, Shen W. Gender differences in insulin resistance, body composition, and energy balance. Gend Med. 2009;6 Suppl 1:60-75.

20. Rebuffe-Scrive M, Bronnegard M, Nilsson A, Eldh J, Gustafsson JA, Bjorntorp P. Steroid hormone receptors in human adipose tissues. $J$ Clin Endocrinol Metab. 1990;71(5):1215-1219.

21. Krotkiewski M, Bjorntorp P, Sjostrom L, Smith U. Impact of obesity on metabolism in men and women. Importance of regional adipose tissue distribution. J Clin Invest. 1983;72(3):1150-1162.

22. Regitz-Zagrosek V, Lehmkuhl E, Mahmoodzadeh S. Gender Aspects of the Role of the Metabolic Syndrome as a Risk Factor for Cardiovascular Disease. Gend Med. 2007;4(Suppl B):S162-S177.

23. Dallongeville J, Cottel D, Arveiler D, et al. The association of metabolic disorders with the metabolic syndrome is different in men and women. Ann Nutr Metab. 2004;48(1):43-50.

24. Szalat A, Raz I. Gender-specific care of diabetes mellitus: particular considerations in the management of diabetic women. Diabetes Obes Metab. 2008;10(12):1135-1156.

25. Hanefeld M, Koehler C, Fuecker K, et al. Insulin secretion and insulin sensitivity pattern is different in isolated impaired glucose tolerance and impaired fasting glucose: the risk factor in Impaired Glucose Tolerance for Atherosclerosis and Diabetes study. Diabetes Care. 2003;26(3):868-874.

26. Goldstein BJ. Insulin resistance as the core defect in type 2 diabetes mellitus. Am J Cardiol. 2002;90(5):3G-10G.

27. Wild S, Roglic G, Green A, Sicree R, King H. Global prevalence of diabetes: estimates for the year 2000 and projections for 2030. Diabetes Care. 2004;27(5):1047-1053.

28. Gale EA, Gillespie KM. Diabetes and gender. Diabetologia. 2001;44(1):3-15

29. Sattar N. Gender aspects in type 2 diabetes mellitus and cardiometabolic risk. Best Pract Res Clin Endocrinol Metab. 2013;27(4):501-507.

30. Awa WL, Fach E, Krakow D, et al. Type 2 diabetes from pediatric to geriatric age: analysis of gender and obesity among 120,183 patients from the German/ Austrian DPV database. Eur J Endocrinol. 2012;167(2):245-254.

31. Lewitt MS, Hilding A, Brismar K, Efendic S, Ostenson CG, Hall K. IGF-binding protein 1 and abdominal obesity in the development of type 2 diabetes in women. Eur J Endocrinol. 2010;163(2):233-242.

32. Lewitt MS, Hilding A, Ostenson CG, Efendic S, Brismar K, Hall K. Insulin-like growth factor-binding protein-1 in the prediction and development of type 2 diabetes in middle-aged Swedish men. Diabetologia. 2008;51(7):1135-1145.

33. Pomerleau J, McKeigue PM, Chaturvedi N. Relationships of fasting and postload glucose levels to sex and alcohol consumption. Are American Diabetes Association criteria biased against detection of diabetes in women? Diabetes Care. 1999;22(3):430-433. 
34. Bjorntorp P. Visceral obesity: a "civilization syndrome". Obes Res. 1993;1(3):206-222.

35. Arnetz L. The HPA Axis in Type 2 Diabetes - Some Aspects in Relation to Insulin Sensitivity, Beta-Cell Function and IGF-I/IGFBP-1 [doctoral thesis]. Stockholm: Department of Molecular Medicine and Surgery, Karolinska Institutet; 2014.

36. Federman DD. The biology of human sex differences. $N$ Engl J Med. 2006;354(14):1507-1514.

37. Mayes JS, Watson GH. Direct effects of sex steroid hormones on adipose tissues and obesity. Obes Rev. 2004;5(4):197-216.

38. Meyer MR, Clegg DJ, Prossnitz ER, Barton M. Obesity, insulin resistance and diabetes: sex differences and role of oestrogen receptors. Acta Physiol (Oxf). 2011;203(1):259-269.

39. Seidell JC, Bjorntorp P, Sjostrom L, Kvist H, Sannerstedt R. Visceral fat accumulation in men is positively associated with insulin, glucose, and C-peptide levels, but negatively with testosterone levels. Metabolism. 1990;39(9):897-901.

40. Tibblin G, Adlerberth A, Lindstedt G, Bjorntorp P. The pituitary-gonadal axis and health in elderly men: a study of men born in 1913. Diabetes. 1996;45(11):1605-1609.

41. Marin P, Krotkiewski M, Bjorntorp P. Androgen treatment of middle-aged, obese men: effects on metabolism, muscle and adipose tissues. Eur J Med. 1992;1(6):329-336.

42. Marin P, Holmang S, Gustafsson C, et al. Androgen treatment of abdominally obese men. Obes Res. 1993;1(4):245-251.

43. Ding EL, Song Y, Malik VS, Liu S. Sex differences of endogenous sex hormones and risk of type 2 diabetes: a systematic review and meta-analysis. JAMA. 2006;295(11):1288-1299.

44. Polderman KH, Gooren LJ, Asscheman H, Bakker A, Heine RJ. Induction of insulin resistance by androgens and estrogens. J Clin Endocrinol Metab. 1994;79(1):265-271.

45. Bjorntorp P. Neuroendocrine perturbations as a cause of insulin resistance. Diabetes Metab Res Rev. 1999;15(6):427-441.

46. Nandi A, Chen Z, Patel R, Poretsky L. Polycystic Ovary Syndrome. Endocrinol Metab Clin North Am. 2014;43(1):123-147.

47. Rincon J, Holmang A, Wahlstrom EO, et al. Mechanisms behind insulin resistance in rat skeletal muscle after oophorectomy and additional testosterone treatment. Diabetes. 1996;45(5):615-621.

48. Korhonen S, Hippelainen M, Vanhala M, Heinonen S, Niskanen L. The androgenic sex hormone profile is an essential feature of metabolic syndrome in premenopausal women: a controlled community-based study. Fertil Steril. 2003;79(6):1327-1334.

49. Barrett-Connor E, Holbrook TL. Sex differences in osteoporosis in older adults with non-insulin-dependent diabetes mellitus. JAMA. 1992;268(23):3333-3337.

50. Wake DJ, Strand M, Rask E, et al. Intra-adipose sex steroid metabolism and body fat distribution in idiopathic human obesity. Clin Endocrinol (Oxf). 2007;66(3):440-446.

51. Rajpathak SN, Gunter MJ, Wylie-Rosett J, et al. The role of insulin-like growth factor-I and its binding proteins in glucose homeostasis and type 2 diabetes. Diabetes Metab Res Rev. 2009;25(1):3-12.

52. Gatford KL, Egan AR, Clarke IJ, Owens PC. Sexual dimorphism of the somatotrophic axis. J Endocrinol. 1998;157(3):373-389.

53. Unden AL, Elofsson S, Knox S, Lewitt MS, Brismar K. IGF-I in a normal population: Relation to psychosocial factors. Clin Endocrinol (Oxf). 2002;57(6):793-803.

54. Hilding A, Brismar K, Degerblad M, Thoren M, Hall K. Altered relation between circulating levels of insulin-like growth factor- binding protein-1 and insulin in growth hormone-deficient patients and insulindependent diabetic patients compared to that in healthy subjects. J Clin Endocrinol Metab. 1995;80(9):2646-2652.

55. Baxter RC. Insulin-like growth factor (IGF)-binding proteins: interactions with IGFs and intrinsic bioactivities. Am J Physiol Endocrinol Metab. 2000;278(6):E967-E976.

56. Unden AL, Elofsson S, Brismar K. Gender differences in the relation of insulin-like growth factor binding protein-1 to cardiovascular risk factors: A population-based study. Clin Endocrinol (Oxf). 2005;63(1):94-102.
57. Cardim HJ, Lopes CM, Giannella-Neto D, da Fonseca AM, Pinotti JA. The insulin-like growth factor-I system and hormone replacement therapy. Fertil Steril. 2001;75(2):282-287.

58. Hu E, Liang P, Spiegelman BM. AdipoQ is a novel adipose-specific gene dysregulated in obesity. J Biol Chem. 1996;271(18):10697-10703.

59. Kadowaki T, Yamauchi T, Kubota N, Hara K, Ueki K, Tobe $\mathrm{K}$. Adiponectin and adiponectin receptors in insulin resistance, diabetes, and the metabolic syndrome. J Clin Invest. 2006;116(7):1784-1792.

60. Halleux CM, Takahashi M, Delporte ML, et al. Secretion of adiponectin and regulation of apM1 gene expression in human visceral adipose tissue. Biochem Biophys Res Commun. 2001;288(5):1102-1107.

61. Maeda N, Takahashi M, Funahashi T, et al. PPARgamma ligands increase expression and plasma concentrations of adiponectin, an adiposederived protein. Diabetes. 2001;50(9):2094-2099.

62. Nishizawa H, Shimomura I, Kishida K, et al. Androgens decrease plasma adiponectin, an insulin-sensitizing adipocyte-derived protein. Diabetes. 2002;51(9):2734-2741.

63. Weyer C, Funahashi T, Tanaka S, et al. Hypoadiponectinemia in obesity and type 2 diabetes: Close association with insulin resistance and hyperinsulinemia. J Clin Endocrinol Metab. 2001;86(5): 1930-1935.

64. Cnop M, Havel PJ, Utzschneider KM, et al. Relationship of adiponectin to body fat distribution, insulin sensitivity and plasma lipoproteins: evidence for independent roles of age and sex. Diabetologia. 2003;46(4):459-469.

65. Spranger J, Kroke A, Mohlig M, et al. Adiponectin and protection against type 2 diabetes mellitus. Lancet. 2003;361(9353):226-228.

66. Dekker JM, Funahashi T, Nijpels G, et al. Prognostic value of adiponectin for cardiovascular disease and mortality. J Clin Endocrinol Metab. 2008;93(4):1489-1496.

67. Unger RH. The physiology of cellular liporegulation. Annu Rev Physiol. 2003;65:333-347.

68. Barrett-Connor E. Sex differences in coronary heart disease: Why are women so superior? The 1995 Ancel Keys Lecture. Circulation. 1997;95(1):252-264.

69. Thomas T, Burguera B, Melton LJ 3rd, et al. Relationship of serum leptin levels with body composition and sex steroid and insulin levels in men and women. Metabolism. 2000;49(10):1278-1284.

70. Soderberg S, Stegmayr B, Stenlund H, et al. Leptin, but not adiponectin, predicts stroke in males. J Intern Med. 2004;256(2):128-136.

71. Wallace AM, McMahon AD, Packard CJ, et al. Plasma leptin and the risk of cardiovascular disease in the west of Scotland coronary prevention study (WOSCOPS). Circulation. 2001;104(25):3052-3056.

72. Piemonti L, Calori G, Mercalli A, et al. Fasting plasma leptin, tumor necrosis factor-alpha receptor 2 , and monocyte chemoattracting protein 1 concentration in a population of glucose-tolerant and glucoseintolerant women: impact on cardiovascular mortality. Diabetes Care. 2003;26(10):2883-2889.

73. Washington EL, Shen JJ. Gender discrepancies in the level of disease progression in hospitalized patients with diabetes. Manag Care Interface. 2006;19(10):21-25.

74. Action to Control Cardiovascular Risk in Diabetes Study Group, Gerstein HC, Miller ME, et al. Effects of Intensive Glucose Lowering in Type 2 Diabetes. N Engl J Med. 2008;358(24):2545-2559.

75. ADVANCE Collaborative Group, Patel A, MacMahon S, et al. Intensive blood glucose control and vascular outcomes in patients with type 2 diabetes. N Engl J Med. 2008;358(24):2560-2572.

76. No authors listed. Effect of intensive blood-glucose control with metformin on complications in overweight patients with type 2 diabetes (UKPDS 34). UK Prospective Diabetes Study (UKPDS) Group. Lancet. S1998;352(9131):854-865.

77. Viberti G, Kahn SE, Greene DA, et al. A diabetes outcome progression trial (ADOPT): an international multicenter study of the comparative efficacy of rosiglitazone, glyburide, and metformin in recently diagnosed type 2 diabetes. Diabetes Care. 2002;25(10): 1737-1743. 
78. McGill JB, Vlajnic A, Knutsen PG, Recklein C, Rimler M, Fisher SJ. Effect of gender on treatment outcomes in type 2 diabetes mellitus. Diabetes Res Clin Pract. 2013;102(3):167-174.

79. Knowler WC, Barrett-Connor E, Fowler SE, et al. Reduction in the incidence of type 2 diabetes with lifestyle intervention or metformin. N Engl J Med. 2002;346(6):393-403.

80. Perreault L, Ma Y, Dagogo-Jack S, et al. Sex differences in diabetes risk and the effect of intensive lifestyle modification in the Diabetes Prevention Program. Diabetes Care. 2008;31(7):1416-1421.

81. Tuthill A, McKenna MJ, O’Shea D, McKenna TJ. Weight changes in type 2 diabetes and the impact of gender. Diabetes Obes Metab. 2008;10(9):726-732.

82. Hu FB, Stampfer MJ, Solomon C, et al. Physical activity and risk for cardiovascular events in diabetic women. Ann Intern Med. 2001;134(2):96-105.

83. Loprinzi PD, Pariser G. Physical activity intensity and biological markers among adults with diabetes: considerations by age and gender. J Diabetes Complications. 2013;27(2):134-140.

84. Penno G, Solini A, Bonora E, et al. Gender differences in cardiovascular disease risk factors, treatments and complications in patients with type 2 diabetes: the RIACE Italian multicentre study. J Intern Med. 2013;274(2):176-191

85. Kramer HU, Ruter G, Schottker B, et al. Gender differences in healthcare utilization of patients with diabetes. Am J Manag Care. 2012;18(7):362-369.

86. Kramer HU, Raum E, Ruter G, et al. Gender disparities in diabetes and coronary heart disease medication among patients with type 2 diabetes: results from the DIANA study. Cardiovasc Diabetol. 2012;11:88.

87. Kautzky-Willer A, Kamyar MR, Gerhat D, et al. Sex-specific differences in metabolic control, cardiovascular risk, and interventions in patients with type 2 diabetes mellitus. Gend Med. 2010;7(6):571-583.

88. Karim A, Slater M, Bradford D, et al. Oral antidiabetic drugs: bioavailability assessment of fixed-dose combination tablets of pioglitazone and metformin. Effect of body weight, gender, and race on systemic exposures of each drug. J Clin Pharmacol. 2007;47(1):37-47.

89. Lyons MR, Peterson LR, McGill JB, et al. Impact of sex on the heart's metabolic and functional responses to diabetic therapies. Am J Physiol Heart Circ Physiol. 2013;305(11):H1584-H1591.

90. Walker EA, Molitch M, Kramer MK, et al. Adherence to preventive medications: predictors and outcomes in the Diabetes Prevention Program. Diabetes Care. 2006;29(9):1997-2002.

91. Biradar V, Moran JL, Peake SL, Peter JV. Metformin-associated lactic acidosis (MALA): clinical profile and outcomes in patients admitted to the intensive care unit. Crit Care Resusc. 2010;12(3): 191-195.

92. Pongwecharak J, Tengmeesri N, Malanusorn N, Panthong M, Pawangkapin N. Prescribing metformin in type 2 diabetes with a contraindication: prevalence and outcome. Pharm World Sci. 2009;31(4):481-486.

93. Benz V, Kintscher U, Foryst-Ludwig A. Sex-specific differences in Type 2 Diabetes Mellitus and dyslipidemia therapy: PPAR agonists. Handb Exp Pharmacol. 2012;(214):387-410.

94. Dorkhan M, Magnusson M, Frid A, Grubb A, Groop L, Jovinge S. Glycaemic and nonglycaemic effects of pioglitazone in triple oral therapy of patients with type 2 diabetes. J Intern Med. 2006;260(2): $125-133$.

95. Akazawa S, Sun F, Ito M, Kawasaki E, Eguchi K. Efficacy of troglitazone on body fat distribution in type 2 diabetes. Diabetes Care. 2000;23(8):1067-1071.

96. Flory JH, Small DS, Cassano PA, Brillon DJ, Mushlin AI, Hennessy S. Comparative effectiveness of oral diabetes drug combinations in reducing glycosylated hemoglobin. J Comp Eff Res. 2014;3(1): 29-39.

97. Esteghamati A, Noshad S, Rabizadeh S, Ghavami M, Zandieh A, Nakhjavani M. Comparative effects of metformin and pioglitazone on omentin and leptin concentrations in patients with newly diagnosed diabetes: a randomized clinical trial. Regul Pept. 2013;182:1-6.
98. Vlckova V, Cornelius V, Kasliwal R, Wilton L, Shakir S. Hypoglycaemia with pioglitazone: analysis of data from the Prescription-Event Monitoring study. J Eval Clin Pract. 2010;16(6):1124-1128.

99. Arnetz L, Dorkhan M, Alvarsson M, Brismar K, Ekberg NR. Gender differences in non-glycemic responses to improved insulin sensitivity by pioglitazone treatment in patients with type 2 diabetes. Acta Diabetologica. 2014;51(2):185-192.

100. Wheeler S, Moore K, Forsberg CW, et al. Mortality among veterans with type 2 diabetes initiating metformin, sulfonylurea or rosiglitazone monotherapy. Diabetologia. Epub June 25, 2013.

101. Pencek R, Blickensderfer A, Li Y, Brunell SC, Anderson PW. Exenatide twice daily: analysis of effectiveness and safety data stratified by age, sex, race, duration of diabetes, and body mass index. Postgrad Med. 2012;124(4):21-32.

102. Buysschaert M, Preumont V, Oriot PR, et al. One-year metabolic outcomes in patients with type 2 diabetes treated with exenatide in routine practice. Diabetes Metab. 2010;36(5):381-388.

103. Damholt B, Golor G, Wierich W, Pedersen P, Ekblom M, Zdravkovic M. An open-label, parallel group study investigating the effects of age and gender on the pharmacokinetics of the once-daily glucagon-like peptide-1 analogue liraglutide. J Clin Pharmacol. 2006;46(6):635-641.

104. Anichini R, Cosimi S, Di Carlo A, et al. Gender difference in response predictors after 1-year exenatide therapy twice daily in type 2 diabetic patients: a real world experience. Diabetes Metab Syndr Obes. 2013;6:123-129.

105. He YL. Clinical pharmacokinetics and pharmacodynamics of vildagliptin. Clin Pharmacokinet. 2012;51(3):147-162.

106. Deacon CF, Holst JJ. Saxagliptin: a new dipeptidyl peptidase-4 inhibitor for the treatment of type 2 diabetes. Adv Ther. 2009; 26(5):488-499.

107. Kajiwara A, Saruwatari J, Sakata M, et al. Risk factors for adverse symptoms during dipeptidyl peptidase-IV inhibitor therapy: a questionnaire-based study carried out by the Japan Pharmaceutical Association Drug Event Monitoring project in Kumamoto Prefecture. Drug Saf. 2013;36(10):981-987.

108. Krepinsky J, Ingram AJ, Clase CM. Prolonged sulfonylurea-induced hypoglycemia in diabetic patients with end-stage renal disease. Am J Kidney Dis. 2000;35(3):500-505.

109. Marbury T, Huang WC, Strange P, Lebovitz H. Repaglinide versus glyburide: a one-year comparison trial. Diabetes Res Clin Pract. 1999;43(3):155-166.

110. Kasichayanula S, Liu X, Lacreta F, Griffen SC, Boulton DW. Clinical pharmacokinetics and pharmacodynamics of dapagliflozin, a selective inhibitor of sodium-glucose co-transporter type 2. Clin Pharmacokinet. 2014;53(1):17-27.

111. Amiel SA, Maran A, Powrie JK, Umpleby AM, Macdonald IA. Gender differences in counterregulation to hypoglycaemia. Diabetologia. 1993;36(5):460-464.

112. Diamond MP, Jones T, Caprio S, et al. Gender influences counterregulatory hormone responses to hypoglycemia. Metabolism. 1993;42(12):1568-1572.

113. Korner A, Wabitsch M, Seidel B, et al. Adiponectin expression in humans is dependent on differentiation of adipocytes and down-regulated by humoral serum components of high molecular weight. Biochem Biophys Res Commun. 2005;337(2):540-550.

114. Wandell PE, Gafvels C. Patients with type 2 diabetes aged 35-64 years at four primary health care centres in Stockholm County, Sweden. Prevalence and complications in relation to gender and socio-economic status. Diabetes Res Clin Pract. 2004;63(3):195-203.

115. Kajiwara A, Miyagawa H, Saruwatari J, et al. Gender differences in the incidence and progression of diabetic retinopathy among Japanese patients with type 2 diabetes mellitus: A clinic-based retrospective longitudinal study. Diabetes Res Clin Pract. 2014;103(3):e7-e10.

116. Afzal N, Zaman S, Asghar A, et al. Negative Association of Serum IL-6 and IL-17 with Type-II Diabetes Retinopathy. Iran J Immunol. 2014;11(1):40-48. 
117. Kostev K, Rathmann W. Diabetic retinopathy at diagnosis of type 2 diabetes in the UK: a database analysis. Diabetologia. 2013;56(1): 109-111.

118. Liu JH, Tung TH, Tsai ST, et al. A community-based epidemiologic study of gender differences in the relationship between insulin resistance/ beta-cell dysfunction and diabetic retinopathy among type 2 diabetic patients in Kinmen, Taiwan. Ophthalmologica. 2006;220(4):252-258.

119. Aaberg ML, Burch DM, Hud ZR, Zacharias MP. Gender differences in the onset of diabetic neuropathy. J Diabetes Complications. 2008;22(2):83-87.

120. Nakhjavani M, Morteza A, Jenab Y, et al. Gender difference in albuminuria and ischemic heart disease in type 2 diabetes. Clin $\mathrm{Med}$ Res. 2012;10(2):51-56.

121. Dickman R, Wainstein J, Glezerman M, Niv Y, Boaz M. Gender aspects suggestive of gastroparesis in patients with diabetes mellitus: a cross-sectional survey. BMC Gastroenterol. 2014;14(1):34.

122. Peek ME. Gender differences in diabetes-related lower extremity amputations. Clin Orthop Relat Res. 2011;469(7):1951-1955.

123. Bruun C, Siersma V, Guassora AD, Holstein P, de Fine Olivarius N. Amputations and foot ulcers in patients newly diagnosed with type 2 diabetes mellitus and observed for 19 years. The role of age, gender and co-morbidity. Diabet Med. 2013;30(8):964-972.

124. Janghorbani M, Hedley AJ, Jones RB, Zhianpour M, Gilmour WH Gender differential in all-cause and cardiovascular disease mortality. Int J Epidemiol. 1993;22(6):1056-1063.

125. Carr MC. The emergence of the metabolic syndrome with menopause. J Clin Endocrinol Metab. 2003;88(6):2404-2411.

126. Welty FK. Women and cardiovascular risk. American J Cardiol. 2001;88(7b):48J-52J.

127. Kalyani RR, Lazo M, Ouyang P, et al. Gender Differences in Diabetes and Risk of Incident Coronary Artery Disease in Healthy Young and Middle-Aged Adults. Diabetes Care. 2014;37(3):830-838.

128. Lundberg V, Stegmayr B, Asplund K, Eliasson M, Huhtasaari F. Diabetes as a risk factor for myocardial infarction: population and gender perspectives. J Intern Med. 1997;241(6):485-492.

129. Manson JE, Colditz GA, Stampfer MJ, et al. A prospective study of maturity-onset diabetes mellitus and risk of coronary heart disease and stroke in women. Arch Intern Med. 1991;151(6):1141-1147.

130. Wu YT, Chien CL, Wang SY, Yang WS, Wu YW. Gender differences in myocardial perfusion defect in asymptomatic postmenopausal women and men with and without diabetes mellitus. JWomens Health (Larchmt). 2013;22(5):439-444.

131. Hung MJ, Hsu KH, Hu WS, Chang NC, Hung MY. C-reactive protein for predicting prognosis and its gender-specific associations with diabetes mellitus and hypertension in the development of coronary artery spasm. PloS One. 2013;8(10):e77655.

132. Martinez-Selles M, Doughty RN, Poppe K, et al. Gender and survival in patients with heart failure: interactions with diabetes and aetiology. Results from the MAGGIC individual patient meta-analysis. Eur $J$ Heart Fail. 2012;14(5):473-479.

133. Legato MJ, editors. Gender and its Impact of Risk Factors for Cardiovascular Disease. In: Principles of Gender-Specific Medicine. San Diego, CA: Elsevier Academic Press; 2004; No 1.

134. Hypertension in Diabetes Study (HDS): I. Prevalence of hypertension in newly presenting type 2 diabetic patients and the association with risk factors for cardiovascular and diabetic complications. J Hypertens. 1993;11(3):309-317.

135. Elveback LR, Connolly DC, Melton LJ 3rd. Coronary heart disease in residents of Rochester, Minnesota. VII. Incidence, 1950 through 1982. Mayo Clin Proc. 1986;61(11):896-900.

136. Walden CE, Knopp RH, Wahl PW, Beach KW, Strandness E Jr. Sex differences in the effect of diabetes mellitus on lipoprotein triglyceride and cholesterol concentrations. N Engl J Med. 1984;311(15):953-959.

137. Mosca L, Manson JE, Sutherland SE, Langer RD, Manolio T, Barrett-Connor E. Cardiovascular disease in women: a statement for healthcare professionals from the American Heart Association. Writing Group. Circulation. 1997;96(7):2468-2482.
138. Schroeder EB, Bayliss EA, Daugherty SL, Steiner JF. Gender differences in cardiovascular risk factors in incident diabetes. Women's Health Issues. 2014;24(1):e61-e68.

139. Hu G, Jousilahti P, Qiao Q, Katoh S, Tuomilehto J. Sex differences in cardiovascular and total mortality among diabetic and nondiabetic individuals with or without history of myocardial infarction. Diabetologia. 2005;48(5):856-861.

140. $\mathrm{Hu}$ G, DECODE Study Group. Gender difference in all-cause and cardiovascular mortality related to hyperglycaemia and newlydiagnosed diabetes. Diabetologia. 2003;46(5):608-617.

141. Kanaya AM, Grady D, Barrett-Connor E. Explaining the sex difference in coronary heart disease mortality among patients with type 2 diabetes mellitus: a meta-analysis. Arch Intern Med. 2002;162(15): 1737-1745.

142. Goldschmid MG, Barrett-Connor E, Edelstein SL, Wingard DL, Cohn BA, Herman WH. Dyslipidemia and ischemic heart disease mortality among men and women with diabetes. Circulation. 1994:89(3):991-997.

143. Lee C, Joseph L, Colosimo A, Dasgupta K. Mortality in diabetes compared with previous cardiovascular disease: a gender-specific meta-analysis. Diabetes Metab. 2012;38(5):420-427.

144. Shekelle PG, Rich MW, Morton SC, et al. Efficacy of angiotensinconverting enzyme inhibitors and beta-blockers in the management of left ventricular systolic dysfunction according to race, gender, and diabetic status: a meta-analysis of major clinical trials. J Am Coll Cardiol. 2003;41(9):1529-1538.

145. Walsh JM, Pignone M. Drug treatment of hyperlipidemia in women. JAMA. 2004;291(18):2243-2252.

146. Shigematsu E, Yamakawa T, Taguri M, et al. Efficacy of ezetimibe is associated with gender and baseline lipid levels in patients with type 2 diabetes. J Atheroscler Thromb. 2012;19(9):846-853.

147. Howard BV, Cowan LD, Go O, Welty TK, Robbins DC, Lee ET. Adverse effects of diabetes on multiple cardiovascular disease risk factors in women. The Strong Heart Study. Diabetes Care. 1998;21(8):1258-1265.

148. Franconi F, Campesi I, Occhioni S, Tonolo G. Sex-gender differences in diabetes vascular complications and treatment. Endocr Metab Immune Disord Drug Targets. 2012;12(2):179-196.

149. Gilbert J, Raboud J, Zinman B. Meta-analysis of the effect of diabetes on restenosis rates among patients receiving coronary angioplasty stenting. Diabetes Care. 2004;27(4):990-994.

150. Jacobs AK, Johnston JM, Haviland A, et al. Improved outcomes for women undergoing contemporary percutaneous coronary intervention: a report from the National Heart, Lung, and Blood Institute Dynamic registry. J Am Coll Cardiol. 2002;39(10):1608-1614.

151. Mehilli J, Kastrati A, Bollwein H, et al. Gender and restenosis after coronary artery stenting. Eur Heart J. 2003;24(16):1523-1530.

152. Legato MJ. Dyslipidemia, gender, and the role of high-density lipoprotein cholesterol: implications for therapy. Am J Cardiol. 2000;86(12A):15L-18L.

153. Orchard TJ. The impact of gender and general risk factors on the occurrence of atherosclerotic vascular disease in non-insulindependent diabetes mellitus. Ann Med. 1996;28(4):323-333.

154. Steinberg HO, Paradisi G, Cronin J, et al. Type II diabetes abrogates sex differences in endothelial function in premenopausal women. Circulation. 2000;101(17):2040-2046.

155. Chan P, Pan WH. Coagulation activation in type 2 diabetes mellitus: the higher coronary risk of female diabetic patients. Diabet Med. 1995;12(6):504-507.

156. Mascarenhas-Melo F, Marado D, Palavra F, et al. Diabetes abrogates sex differences and aggravates cardiometabolic risk in postmenopausal women. Cardiovasc Diabetol. 2013;12:61.

157. Nakhjavani M, Morteza A, Meysamie A, et al. Serum heat shock protein 70 and oxidized LDL in patients with type 2 diabetes: does sex matter? Cell Stress Chaperones. 2011;16(2):195-201.

158. Schenck-Gustafsson K. Diagnosis of cardiovascular disease in women. Menopause Int. 2007;13(1):19-22. 
159. Zelenko Z, Gallagher EJ. Diabetes and Cancer. Endocrinol Metab Clin North Am. 2014;43(1):167-185.

160. Vestergaard P, Starup-Linde J. Diabetes, cancer and treatment a mini-review. Curr Drug Saf. 2013;8(5):292-295.

161. Kramer HU, Muller H, Stegmaier C, Rothenbacher D, Raum E, Brenner H. Type 2 diabetes mellitus and gender-specific risk for colorectal neoplasia. Eur J Epidemiol. 2012;27(5):341-347.

162. Tseng $\mathrm{CH}$. Diabetes and risk of bladder cancer: a study using the National Health Insurance database in Taiwan. Diabetologia. 2011;54(8):2009-2015.

163. Chiou WK, Hwang JS, Hsu KH, Lin JD. Diabetes mellitus increased mortality rates more in gender-specific than in nongender-specific cancer patients: a retrospective study of 149,491 patients. Exp Diabetes Res. 2012;2012:701643.

164. Sun GE, Wells BJ, Yip K, et al. Gender-specific effects of oral hypoglycaemic agents on cancer risk in type 2 diabetes mellitus. Diabetes Obes Metab. 2014;16(3):276-283.

165. Siddiqui MA, Khan MF, Carline TE. Gender differences in living with diabetes mellitus. Materia Sociomed. 2013;25(2):140-142.

166. Anderson RJ, Freedland KE, Clouse RE, Lustman PJ. The prevalence of comorbid depression in adults with diabetes: a meta-analysis. Diabetes Care. 2001;24(6):1069-1078.
167. Muller G, Hartwig S, Greiser KH, et al. Gender differences in the association of individual social class and neighbourhood unemployment rate with prevalent type 2 diabetes mellitus: a crosssectional study from the DIAB-CORE consortium. BMJ Open. 2013;3(6):1-11.

168. Eriksson AK, Ekbom A, Granath F, Hilding A, Efendic S, Ostenson CG. Psychological distress and risk of pre-diabetes and Type 2 diabetes in a prospective study of Swedish middle-aged men and women. Diabetic Med. 2008;25(7):834-842.

169. Eriksson AK, van den Donk M, Hilding A, Ostenson CG. Work stress, sense of coherence, and risk of type 2 diabetes in a prospective study of middle-aged Swedish men and women. Diabetes Care. 2013;36(9): 2683-2689.

170. Svenningsson I, Bjorkelund C, Marklund B, Gedda B. Anxiety and depression in obese and normal-weight individuals with diabetes type 2: a gender perspective. Scand J Caring Sci. 2012;26(2): 349-354.

171. Nau DP, Aikens JE, Pacholski AM. Effects of gender and depression on oral medication adherence in persons with type 2 diabetes mellitus. Gend Med. 2007;4(3):205-213.

\section{Publish your work in this journal}

Diabetes, Metabolic Syndrome and Obesity: Targets and Therapy is an international, peer-reviewed open-access journal committed to the rapid publication of the latest laboratory and clinical findings in the fields of diabetes, metabolic syndrome and obesity research. Original research, review, case reports, hypothesis formation, expert opinion and commentaries are all considered for publication. The manuscript management system is completely online and includes a very quick and fair peer-review system, which is all easy to use. Visit http://www.dovepress.com/testimonials.php to read real quotes from published authors. 